\title{
Economic analysis of a horizontal diabatic separation system
}

\author{
Papadakis, Emmanouil; Huusom, Jakob K.; Abildskov, Jens
}

Published in:

Chemical Engineering Research and Design

Link to article, DOI:

10.1016/j.cherd.2019.05.023

Publication date:

2019

Document Version

Peer reviewed version

Link back to DTU Orbit

Citation (APA):

Papadakis, E., Huusom, J. K., \& Abildskov, J. (2019). Economic analysis of a horizontal diabatic separation system. Chemical Engineering Research and Design, 147, 709-720. https://doi.org/10.1016/j.cherd.2019.05.023

\section{General rights}

Copyright and moral rights for the publications made accessible in the public portal are retained by the authors and/or other copyright owners and it is a condition of accessing publications that users recognise and abide by the legal requirements associated with these rights.

- Users may download and print one copy of any publication from the public portal for the purpose of private study or research.

- You may not further distribute the material or use it for any profit-making activity or commercial gain

- You may freely distribute the URL identifying the publication in the public portal

If you believe that this document breaches copyright please contact us providing details, and we will remove access to the work immediately and investigate your claim 


\section{Economic analysis of a horizontal diabatic separation system}

2 Emmanouil Papadakis, Jakob K. Huusom, Jens Abildskov*

3 PROSYS, Department of Chemical and Biochemical Engineering, Technical University of

4 Denmark, Søltofts Plads, Building 229, DK-2800 Kgs. Lyngby, Denmark, ja@kt.dtu.dk

\section{Abstract}

6 Model-based methods and tools are applied to preliminary analysis of a mobile heat integrated horizontal separation system. An economic model, based on Guthrie's modular approach, is developed for analysis of capital and operational expenditures. The separation system consists of two, co-axially arranged tubes. The inner one is serving as a stripping section and the outer one as rectifying section. First, a steady state model is developed using $n$ non-equilibrium stages based on mass transfer modeling. Sensitivity analysis has been performed to assess the impact on system performance, of variations of transport coefficients and design variables. The model together with an economic model has been applied to identify design and operational limitations on such a unit. The analysis investigates the total annual cost dependence of heat transfer area, alcohol concentration in the feed and rejected amount of water in the stripping section for different locations of interest. It has been found that the overall operating costs are significantly reduced for higher alcohol concentration in the feed and high discharge of water at the end of the stripping section. On the other hand, increased heat transfer area between the stripping and rectifying section leads to higher capital costs and is not necessarily balanced by lower operating costs.

Keywords: Biofuels, local biorefineries, process modelling, separations, process analysis and evaluation.

\section{Introduction}

During the last decade the consideration of using bio-fuels and chemicals produced from secondgeneration (2G) biomass (lignocellulosic materials) and first-generation (1G) biomass (sugarcane and corn) has received much attention (Almeida et al. 2012). Even though advances of process technology is a very important factor for bio-refineries, sustainable and economically viable biofuels production also depends on other factors (Aditiya et al. 2016). One important consideration, for reducing the expenditures, is the reduction of costs associated with transportation (Bossl et al 2010).

Here, a concept is explored, consisting of a small-scale modular separation system, where each module is expected to deliver $5000-15000 \mathrm{~m}^{3} /$ year of ethanol. This appears almost tailor made for mobile refineries, to enable manufacture of customized products at various locations. A container format (diameter $<2 \mathrm{~m}$, length $<6 \mathrm{~m}$ ) can facilitate transportation to reap the benefits of localized service delivery without duplication of equipment at multiple locations. For this purpose, we consider a horizontal container format, inspired by previous patents (Eckey 1959, Wyss 1980 and 
We focus on separation of mixtures containing light alcohols from small-scale production facilities of alcohols. Real mixtures after fermentation usually consists of yeast (solid phase), water, and small amounts of light and heavy alcohols, aldehydes, esters, ketones, acetyls and carboxylic acids (Bisgaard et al. 2017a). The focus of this separation system is to separate light and heavier alcohols from the remaining heavier compounds after the fermentation process. The separation unit can replace the beer column that is used to remove the water and concentrate the fermentation stream (Bisgaard et al. 2017a). Due to large heat transfer surface and small temperature differences, a horizontal system may allow a mild thermal treatment compared to classical distillation systems. This may preserve the activity of recovered enzymes in the heavy product and reduce the risk of fouling liquids. Also, a reboiler is considered here, but open steam could also be used, since water is dominant in the stripping section.

The concept of horizontal separation columns is not new. Much-smaller-scale "zero-gravity" separation of binary mixtures (ethanol/water, methanol/water) in cases of total reflux and product removal was experimentally investigated by Seok et al. (1985). Their horizontal system consisted of a pipe, with heating and cooling areas. When a mixture entered the pipe, at steady state, vapor and liquid would flow counter-currently. The volatile component would evaporate towards the cooling end and the less volatile compound towards the heating end. Seok et al. (1985) accomplished the separation using a horizontal system in a shorter unit when compared to the conventional vertical distillation column. Later, Ramirez-Gonzalez et al. (1992) developed a mathematical model, with transport numbers from correlations (for packed columns), equilibrium at an interface and bubblepoint conditions. Their model was validated using the results of Seok and Hwang. Much more recently, Kim et al. (2013) reported a horizontal system (rectangular shaped) consisting of a stripping and a rectifying section, with the feed entered at the middle of the column. Heat was supplied to the stripping section, removed from the rectifying section without the need for reflux or re-boiling at the ends of the column. The mixture of methanol/n-propanol was used in the rectangular distillation system for evaluation. Compared to conventional distillation column $25.7 \%$ less energy demand was demonstrated. The rectangular shaped column (Jang and Kim (2015)) has 1.5 times bigger cross-sectional area when compared to the circular column with identical nominal size characteristics (Seok et al. 1985). Thus, larger throughput can be achieved due to increased capacity of the rectangular column because of the higher cross-sectional area. However, with regards to energy efficiency, Jang and Kim (2015) reported similar energy demands between the circular and rectangular columns even if the change in shape led to increased equipment capacity. Thus, the energy efficiency is not affected by the different sizes of cross-sectional area in the horizontal columns but the diabatic operation proposed by Jang and Kim (2015) has reduced the energy requirement of the horizontal columns in comparison to a vertical system achieving the same separation. At industrial scale, several evaporation systems used in bioindustries have for decades been horizontal and diabatic (Jensen 2005) at the same time using mechanical rotors for enhancing vapour/liquid phase contact.

Separations controlled by mass transfer rates are usually modeled using a non-equilibrium stage model such as that described by Krishnamurthy and Taylor (1985; and several later papers). Over years, rate-based models have been applied to analysis of increasingly complex distillation systems, 
such as packed distillation columns (Lee et al., 1997), reactive packed distillation columns in steady-state (Peng et al., 2002) and dynamic mode (Peng et al., 2003), reactive distillation in dividing wall columns (Mueller and Kenig, 2007) and modelling of heat integrated air separation columns (Chang et al., 2014).

Here, such a steady state mass transfer model that represents qualitatively the system is developed for analysis. It employs heat integration between the stripping and rectifying section and an economic model is used for the calculation of the capital and the operating costs. We use it here

1) for sensitivity analysis studies to investigate the effect of the transport coefficient uncertainties, and

2) to investigate effects of process specifications and design variables on process performance criteria and energy demands, and

3) to calculate the equipment cost by combining it with an economic model

Through process analysis (energy and economics), operational and design limitations are identified. In the following sections, the separation system is first described more closely, then the model development and analysis is summarized, followed by the results of the sensitivity analysis and simulation studies. Finally, process evaluation in terms of economics is discussed and conclusions are made.

\section{System description}

A horizontal separation system is shown in Figure 1. It has two tubes. The one (forming the stripping section) is placed coaxially inside the other (rectifying section). The overall length of the system is $6 \mathrm{~m}$, inner diameter $1.8 \mathrm{~m}$ and outer tube diameter $2 \mathrm{~m}$. The feed is considered to be light alcohols and water. In reality, a series of organic trace components and temperature sensitive enzymes are also present, but these are not explicitly considered here. The feed flow enters the stripping section at reduced pressure to preserve temperature sensitive enzymes used in fermentation. The liquid phase moves towards the end of the system by pumping, perhaps assisted by a slight inclination of the unit (not shown), and a pressure drop. This is different from the zerogravity distillation systems driven by capillary forces. In the stripping section, evaporation takes place, and the less volatile compounds are collected as a heavy product (stillage). Evaporation is enhanced when liquid phase is distributed as droplets, created by mechanical means (e.g. rotors) in the stripping section (also not shown). The heavy product of the stripper consists of water and valuable compounds. The light product consists of more light alcohols. The strippers light product is compressed to a higher pressure and charged into the rectifying section, where the alcohols are collected as light product, whereas the bottom product is returned to the stripper after pressure reduction. Thus, due to pressure differences, heat transfer takes place from the rectifying to the stripping chambers (Papadakis et al. 2018). A pressure drop is expected, but on mass transfer rates and phase equilibria this has minor impact, so we will ignore this in the following. 


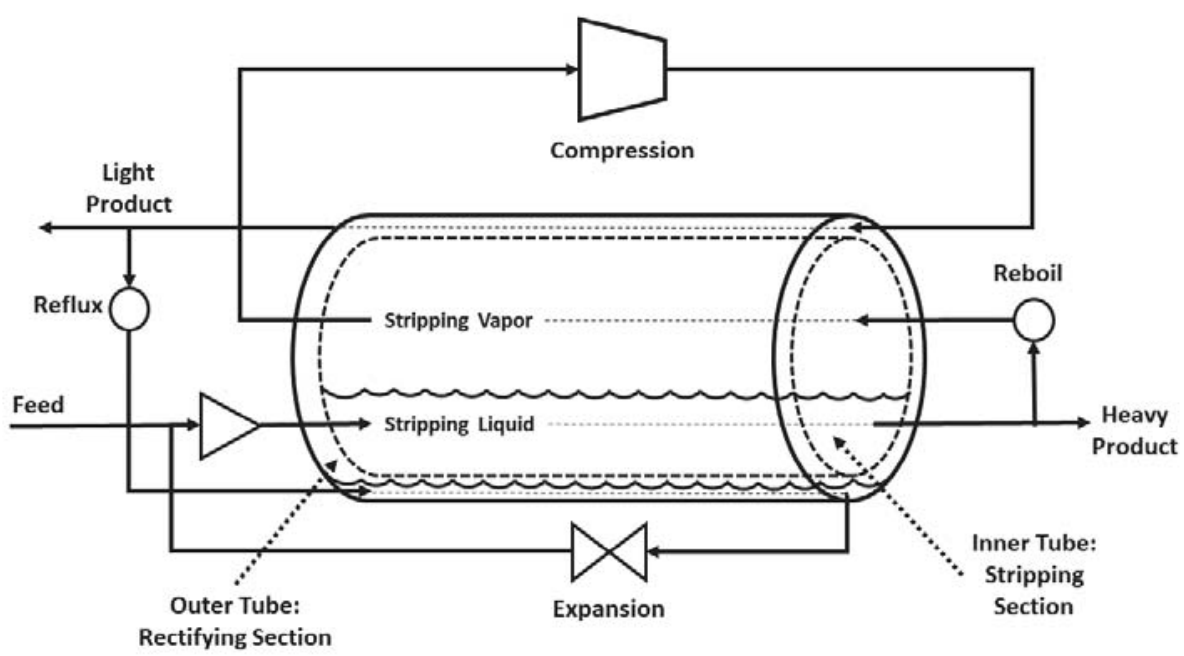

115 Figure 1. Heat integrated horizontal separation system. The stripping section is the inner tube (dashes), while 116 the outer tube (full line) is the rectifying section. Container formats constrain the overall length to $6 \mathrm{~m}$, inner diameter to $1.8 \mathrm{~m}$ and outer tube diameter to $2 \mathrm{~m}$.

\section{System Model Development}

The model is developed in a fashion, resembling that of Heitzig et al. (2012), implying four phases: In Phase I the problem is defined, based on model development objectives together with a description of the system, phenomena, assumptions and available data. In Phase II, a mathematical model is constructed, analyzed and evaluated. In the phase III, sensitivity analysis is performed and finally, in Phase IV simulation studies are made.

\subsection{Phase I. Problem definition}

\subsubsection{Modelling development objective}

The objective is to develop a steady state model reflecting the fundamental phenomena taking place in a diabatic horizontal separation system. The model needs to describe, qualitatively, for both rectifying and stripping sections internal flow rate profiles, the temperature and the composition profiles in the vapor and liquid phases. The model, at steady state, should be applicable to simulation studies, sensitivity analysis, evaluation and analysis of economics and energy consumption as well as for design studies.

\section{$132 \quad 3.1 .2$ System description}

133 The overall system is described in Section 2. For model construction, the system is broken down 134 into a number of segments, $N$. Figure 2 shows how $N$ segments (non-equilibrium stage) for the 135 rectifying and stripping sections, a compressor, a reboiler, a condenser and a valve is combined to 136 represent the overall system. Figure 2 also indicates heat transfer between the two segments in 137 different sections $\left(\mathrm{Q}_{\mathrm{j}}, \mathrm{j}=1, N\right)$, the overall heat transfer area $\left(\mathrm{UA}_{\mathrm{j}}, \mathrm{j}=1, N\right)$, the reboiler and 138 condenser duty $\left(\mathrm{Q}_{\text {reb }}\right.$ and $\mathrm{Q}_{\text {con }}$ respectively) and the compressor work $\left(\mathrm{W}_{\mathrm{c}}\right)$. The system has been 139 divided into 30 segments $(N=30)$. Lower segments numbers have also been tested. The results 140 have been compared in an initial analysis step. No difference in terms of system performance was 
141 found, although the internal profiles (temperature, flow rate and composition) were somewhat more 142 accurate (Papadakis et al. 2018a).

143

144

145

146

147

148

149

150

151

152

153

154

155

156

157

158

159

160

161

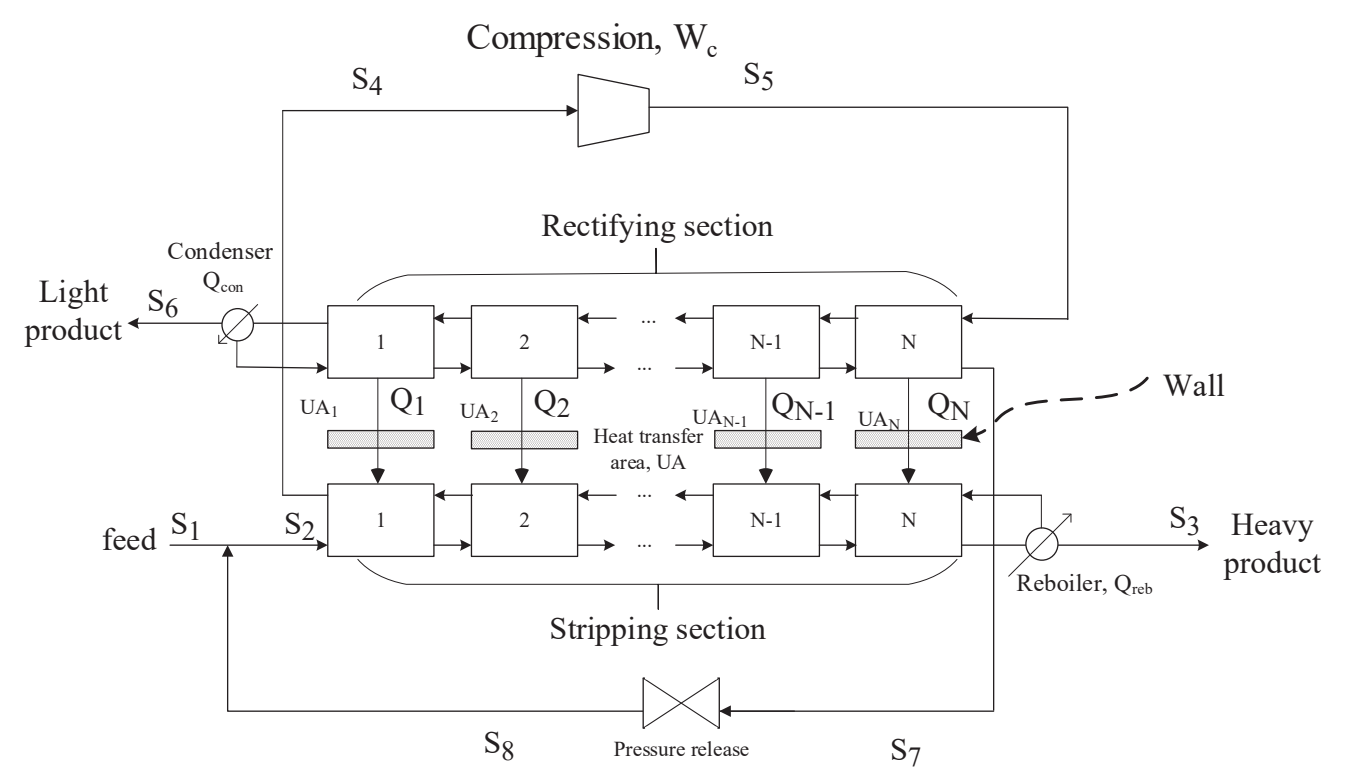

Figure 2. Representation of the separation system resolved into $\mathrm{N}$ segments. The description of the system shows key elements of the model, the $\mathrm{N}$ segments of the stripping and rectifying section, the reboiler and condenser duty, the recycle, compressor and the heat transfer area.

\subsubsection{System phenomena and assumptions}

The following phenomena are considered to build/construct the system model:

- Mass transfer controlled separation. The system has no trays and equilibrium between bulk states cannot be assumed, so mass transfer controls the separation and MERSHQ (Mass Energy Rate Summation Hydraulic equilibrium) type equations are applied.

- Counter-current flow of vapor and liquid phases in both chambers.

- Heat transfer between the rectifying and stripping section is realized given a sufficient temperature gradient $\left(\Delta \mathrm{T}_{\min }=5 \mathrm{~K}\right)$, created by compressing the light product of the stripper before it enters the rectifying section.

- Compression of the strippers exiting vapor and pressure reduction of the rectifiers (outlet) liquid.

The following assumptions are made to develop the model:

- Rate-based separation. Liquid and vapor phases are not at equilibrium at any position in the sections. Vapor-liquid equilibrium only occurs at the interface.

- The pressure of the rectifying and stripping sections, are perfectly controlled. 
- Pressure drop over the length of the stripping and rectifying sections is ignored.

- Condenser and reboiler are modelled as equilibrium stages.

- The outer wall of the rectifying section is thermally insulated.

- Heat transfer coefficients are calculated using the Chilton and Colburn analogy (Taylor and Krishna, 1993).

- Due to lack of mass and heat transfer correlations and/or experimental data to develop accurate correlations for the present system, mass transfer coefficients are estimated using the gauze packing correlations of Bravo et al. (1985). Thus, the transport numbers, mass transfer coefficients, heat transfer coefficient and interfacial area must be realized for the conclusions to resemble reality. While the numbers are probably not correct, sensitivity analysis of their effect on the system performance will be made.

\subsection{Phase II. Model development}

\subsubsection{Model construction}

The liquid activity coefficients are calculated using the Wilson equation with regressed binary interaction parameters (ASPEN Plus - version 8.8) from experimental VLE data (NIST for pressures 0.3 bar -1.0 bar). The Wilson equation has the advantage that it does not predict a false liquid-liquid phase split, and thus there is no need to worry about phase (in)stability. The resulting model consists of non-linear implicit algebraic equations (AEs) and are solved using ASPEN Plus and the RadFrac model library.

\subsubsection{Modelling the heat transfer between the rectifying and stripping section}

The rectifying section operates at higher pressure, to ensure sufficient temperature difference between the sections. The heat transferred from the rectifying to the stripping section per segment $j$ is:

$$
Q_{j}^{W}=n \cdot U_{j} \cdot A_{j} \cdot \Delta T_{j}
$$

where $U_{j}$ is the overall heat transfer coefficient in $\frac{k W}{m^{2} K}, A_{j}$ is the heat transfer area in $m^{2}$, and $\Delta T_{j}$ is the temperature difference between the liquid phases of the rectifying and the stripping section $\Delta T_{j}=T_{j}^{L, R}-T_{j}^{L, S}$ in $\mathrm{K}$. For the overall heat transfer coefficient, a value of $1 \frac{\mathrm{kW}}{\mathrm{m}^{2} \mathrm{~K}}$ has been chosen. The variable $n$ has been introduced. It takes values equal to or greater than unity $(n \geq 1)$, and is used to evaluate the effect of the heat transfer area on the performance of the separation system. The heat transfer area has been calculated considering that the default area per segment $j$, is the surface area of the stripping segment $j$ considering that the segment $j$ has a cylindrical shape. Thus, by multiplying by the overall heat transfer coefficient, the product $U_{j} A_{j}$ is obtained. Additionally, the temperature profiles for the rectifying and stripping section are obtained through simulations when no heat integration is considered. Once all the right-hand side variables of Eq. (1) are known, heat integration is imposed on the model calculations by increasing the transfer area. This process is 
iterative. Thus, while the value of the product $U_{j} A_{j}$ is uncertain, its effect on the separation performance can be assessed, using different values of $n$. The minimum value of the heat transfer area has been considered as the external surface area of the stripper. Evaluating the effect of the heat transfer area may lead to important conclusions regarding operational and design issues. For example, increasing the heat transfer area may reduce the energy requirements of the system (especially the reboiler duty for the stripping section) but perhaps this is only advantageous up to a certain level. Thus, it may provide indications of the scope of developing further the contact surface to increase the area available for heat transfer.

\subsubsection{Economic analysis}

For the economic analysis, an approach similar to Bisgaard et al. (2015), has been taken. They developed economic models for comparisons of heat integrated distillation systems using the Guthrie's modular method for the estimation of CAPEX as described by Biegler (1997) and Timmerhaus (2003). For the horizontal, heat integrated, separation system, the estimate of CAPEX is the summation of the updated base module costs (UMCs) which correspond to a horizontal evaporator (stripping section), a horizontal vessel (rectifying section), a compressor, and heat exchangers for the reboiler and condenser. The stripping section has been considered as a horizontal evaporator and it is priced based on available heat exchange area. The following expression gives the base cost (BC):

$$
\ln (B C)(\$ @ 2007)=9.6231+0.53[\ln A]
$$

Here $\mathrm{A}$ is the heat transfer area in $\mathrm{m}^{2}$. The reboiler and condenser are priced as heat exchangers based on the heat transfer area. The BC of the heat exchanger (reboiler and condenser) is calculated from Eq. (3)

$$
B C(\$ @ 1968)=477 A^{0.65}
$$

Again $\mathrm{A}$ is the heat exchange area in $\mathrm{m}^{2}$. The rectifying area is considered as a horizontal vessel and the $\mathrm{BC}$ is calculated from Eq. (4)

$$
B C(\$ @ 1968)=645 L^{0.78} D^{0.98}
$$

Where $\mathrm{L}$ is the length of the vessel in $\mathrm{m}$ and $\mathrm{D}$ the diameter of the vessel in $\mathrm{m}$. Finally, the BC of the compressor is given from Eq. (5)

$$
B C(\$ @ 1968)=515 P^{0.82}
$$

Where $\mathrm{P}$ is the power input. The details of these equations and the way to calculate the base modular cost (BM) is covered by Biegler (1997). The value of the chemical engineering plant cost index ${ }^{1}$ for 2017 is taken to be 562 .

\footnotetext{
${ }^{1}$ https://www.scribd.com/document/352561651/CEPCI-June-2017-Issue. Accessed February 2018
} 


\subsubsection{Model solution}

The heat integrated separation system has been solved (input variables are listed in Table 1) over the tube length, the internal flow rate, temperature and composition profiles have been obtained (Papadakis et al 2018a). The solution has shown that the flow rate has the maximum value for both vapor and liquid phases at the location of feed (stream S2, Figure 2). The internal flow rate of the liquid phase reduces towards the tube end due to evaporation taking place in the stripping section. The flow rate of the vapor phase increases towards the start of the tube due to the evaporation of the liquid. Similarly, in the rectifying section, the model solution shows that the vapor flow rate decreases from the end towards the start of the tube and the liquid flow rate increases towards the end of the column due to condensation (Papadakis et al. 2018a). In the stripping section, the temperature profiles are nearly constant, close to the boiling point of the mixture and lower than $60^{\circ} \mathrm{C}$ (maximum temperature limit in the stripper, to enable recycling of enzymes). In the rectifying section, the temperature is high at the inlet of the rectifying section (length at $6 \mathrm{~m}$ ) due to the vapor compression and reduces towards the end of the rectifier due to heat transfer to the stripping section (Papadakis et al. 2018a). In the stripping section, the ethanol composition reduces towards the end of the tube meaning that no ethanol is in the heavy product. In the rectifying section, the composition of ethanol increases from the inlet towards the end of tube due to the condensation process. Therefore, the model qualitatively can adequately predict an expected system behaviour and it can be used to preliminarily evaluate different operational and process design scenarios, and to sensitivity analysis.

\section{Sensitivity analysis of operational variables}

\subsection{Heat and mass transport coefficients}

Critical unknowns of this model are the transport numbers obtained from known transport correlations for gauze packing material. Although the present conditions are not expected to be equivalent to gauze packings, these default values are chosen in the absense of experimental data for validation of mass and heat transfer correlations. Therefore, one objective of the sensitivity analysis is investigation of how changes in a range of assumed (though realistic) transport numbers may (or may not) affect the performance of the system in terms of energy requirements. The changes in transport coefficients were evaluated by introducing a factor ( $f$ ) that multiplies the calculated coefficient. The principle is that, when the factor equals 0.8 , the calculated transport number times 0.8 is used for the simulation. The sensitivity analysis examines only positive factor values less than unity $(0<f \leq 1)$. Values of the factor $f$ above 1 were not part of the sensitivity analysis, since the purpose is to examine how the overall system performance changes when poorer transport numbers result. As a result of the analysis, the mass transfer coefficients for the liquid and vapor phase $\left(k^{L}\right.$ and $\left.k^{V}\right)$ and the heat transfer coefficient, $h$, affect the system and lead to infeasible operation only when their values is $80-99 \%$ lower compared to the ones calculated using gauze packing material.

\subsection{Phase contact area}

The phase contact area between the two phases affects the mass and heat transfer between phases in the stripping and/or the rectifying section. With increased phase contact area, the performance of 
the system is expected also to lower the energy demands. From the analysis, it is noted that the performance of the system in terms of energy and productivity is compromised significantly below a value of about $25 \mathrm{~m}^{2} / \mathrm{m}^{3}$ and above that the system performance remains relatively unaffected - no further improvement is then possible by putting more transfer area. However, the design of such a system must be made carefully as in the case of very small droplets, the phase contact area will be enhanced but at the same time, the droplets might be entrained by vapor flow in the opposite direction. Additionally, adding pumps in systems will certainly increase the phase contact area but also add complexity in manufacturing and capital cost will increase.

273

274

275

276

277

278

279

280

281

282

283

284

285

286

287

288

289

290

291

292

293

294

\section{Simulation studies}

The steady state model can be used to evaluate how changes in process specifications affect energy consumption. Three types of simulation studies have been made. In each simulation the reflux and boil up ratios are determined (using the spec/vary option in ASPENplus) to satisfy the imposed process requirements (such as purity). The first simulation study deals with the evaluation of the overall energy system requirements for different ethanol recovery in the stripping section and ethanol purity in the rectifying section. The second simulation study, examines the effect of increased heat transfer area on system performance. Finally, the third simulation study examines the effect of removing the maximum possible amount of water in the stripping section, with respect to the ethanol feed concentration and heat transfer area.

\subsection{Simulation study 1. Ethanol recovery in stripping and ethanol purity in the rectifying} sections.

Figure 3 shows the energy requirements per $\mathrm{kg}$ of ethanol obtained as a light product from the rectifying section. Not unexpectedly, requirements for reflux reduce when the purity specifications decrease. Additionally, the energy requirement increases substantially when the ethanol recovery is high in the stripping section. The ethanol recovery in the stripping section is the amount of ethanol that is boiled up and returned to the stripping section compared to the amount of ethanol in stream $\mathrm{S} 2$. The reason for the reflux ratio increase is that higher flow rates exit the stripping section and enter the compressor and rectifying section. However, when looking (Figure 3) at the overall energy requirements (condenser and reboiler duties and compressor work) per $\mathrm{kg}$ of ethanol, it is clear that the energy requirements depend, mainly, on the recovery of the ethanol in the stripping section (when it is high), and it is relatively insensitive to the ethanol purity in the rectifying section. 


\section{Energy requirments per $\mathrm{kg}$ of product of vs. ethanol recovery for different ethanol purities}

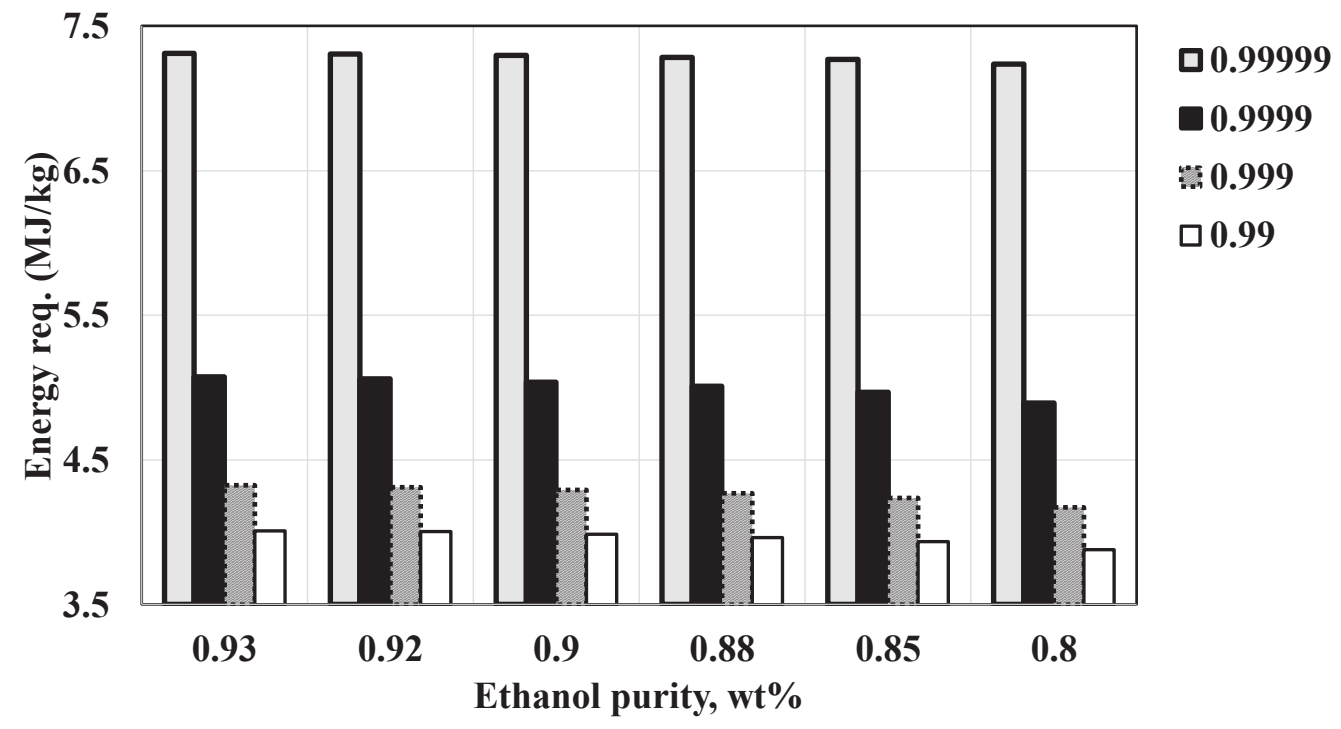

Figure 3. Dependence energy requirements $(\mathrm{MJ} / \mathrm{kg}$ ) with respect to the ethanol purity (wt\%) in the rectifying section for different recovery ratios of ethanol in the stripping section Note: Recovery of ethanol in the stripping section refers to the amount of ethanol that is boiled up and returned in the stripping section compared to the amount of ethanol in stream 2 (S2), see Figure 2. Ethanol purity in wt.\% in the rectifying section refers to the composition of the stream 6 (S6), see Figure 2 (Papadakis et al. 2018b).

The dependence of process variables (boil-up and reflux ratio) and performance criteria (energy requirements in $\mathrm{MJ} / \mathrm{hr}$ and $\mathrm{MJ} / \mathrm{kg}$ ) on ethanol purity in the rectifying section for different values of ethanol recovery in the stripping section have been investigated by Papadakis et al. (2018b). The changes in vapor and liquid flow rates are the main reason for the differences in overall system performance. Concluding from simulation study 1 , the specifications in the stripping section are crucial to system performance as it affects the flow rates entering the compressor and rectifying section. So, not losing ethanol is expensive. On the other hand, the effect of varying the product quality in the rectifying section seems insignificant.

\subsection{Simulation study 2. Effect of heat transfer area}

Heat integration, as explained, takes place between the rectifying and the stripping section. A sufficient temperature difference is necessary and is ensured through compression of the stripper's light product stream that becomes the feed (after compression) to the rectifying section. Additionally, efficient heat transfer area is required as well. Since this area can be varied by mechanical surface design (foldings etc.), it is interesting to evaluate the effect of the heat transfer area on the system performance and possibly identify potential design limitations. The calculation of the heat transfer from the rectifying to the stripping section has been explained in section 3.2.2. It is evaluated using $n$-values of 1,2,3 and 5. Keeping therefore, the ethanol recovery in stripping section at high levels (99.999\%), and the system performance constant, the simulation results are shown in Figure 4 in terms of boil-up ratio (Figure 4a), reflux ratio (Figure 4b), energy requirements in $\mathrm{MJ} / \mathrm{hr}$ (Figure 4c) and $\mathrm{MJ} / \mathrm{kg}$ (Figure $4 \mathrm{~d}$ ) as function of the ethanol purity in the 
rectifying section. The results in Figure 4, show the decrease in energy requirements (Figure 4c and Figure 4d) and in operating variables (boil-up ratio in Figure 4a and reflux ratio in Figure 4b) when the heat transfer area increases.
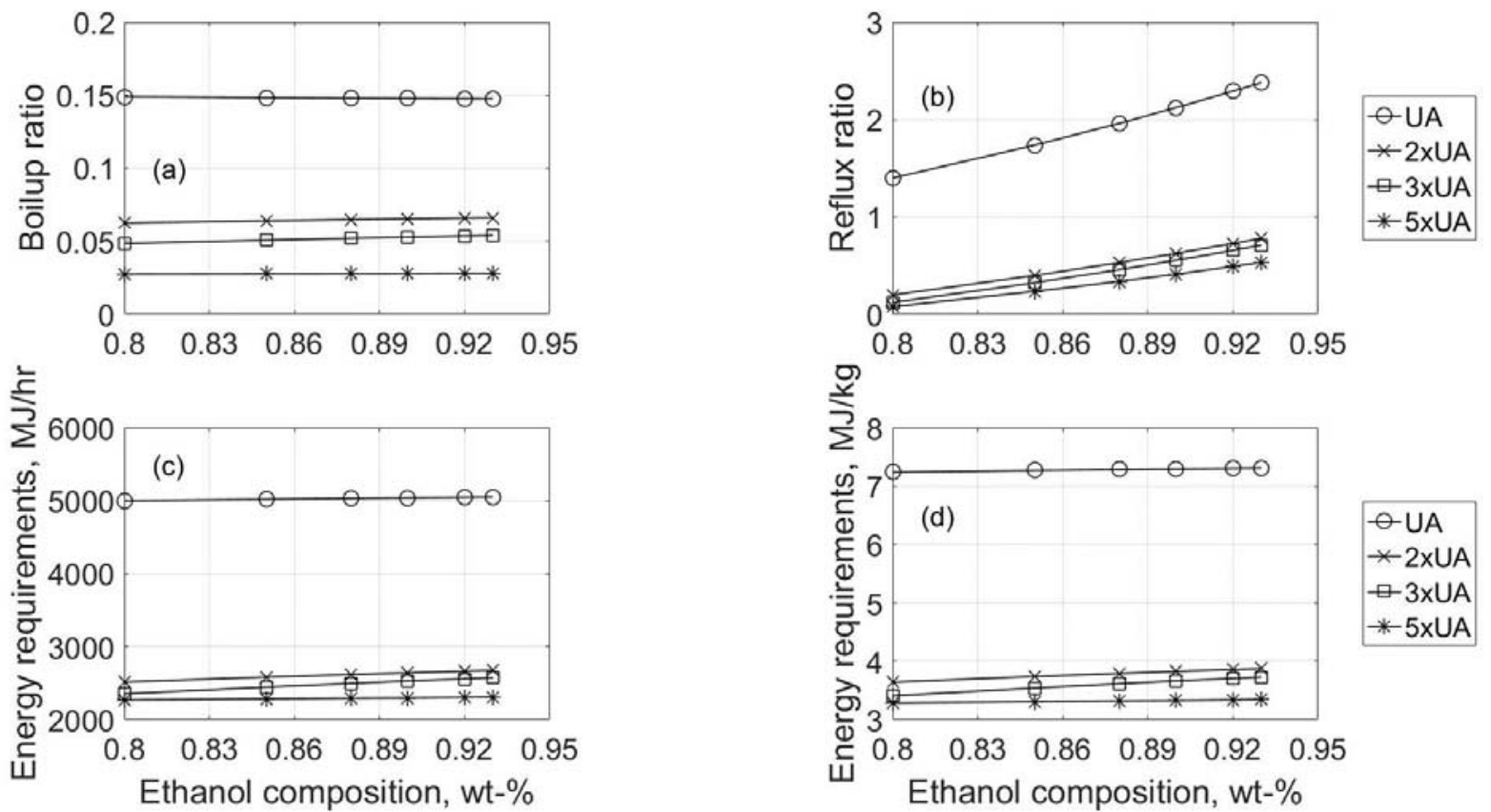

Figure 4. Dependence of operational variables and performance criteria with ethanol product purity (wt-\%) in the rectifying section and heat transfer area. (a) Boil-up and (b) Reflux ratio, (c) Energy requirements in $\mathrm{MJ} / \mathrm{hr}$ and (d) in $\mathrm{MJ} / \mathrm{kg}$ of product. Note that Figure $4 \mathrm{~d}$ has been generated by dividing the energy requirements (Figure $4 \mathrm{c}$ ) in $\mathrm{MJ} / \mathrm{hr}$ by the mass ethanol flowrate in the light stream in the rectifier (Papadakis et al. 2018b).

Thus, heat transfer area and specifications in the stripping section have great impact on the system performance in terms of energy requirements (reflux ratio), whereas specifications in the rectifying section have a small impact on system performance, regardless of the heat transfer rate.

\subsection{Simulation study 3: Identification of design and operational limits}

Next we examine and map the effect of ethanol feed concentration, heat transfer area and water recovery $\left(R_{w}\right)$ in the stripping section (water recovery in the stripping section is the ratio of the amount of water removed as a heavy product from the stripping section (stream 3, S3) and the amount of the water that enters the column in the stream 2 (S2), (see Figure 2) and on the energy requirements per $\mathrm{kg}$ of product (ethanol in the rectifying section, 93 wt.\%). Concentrating the obtained mixtures after the fermentation step, leads to significant reduction in energy requirements of subsequent separation steps in the downstream process. The results are shown in Figure 5. Figure 5 shows the energy requirements in terms of reboiler and condenser duty and compressor work. In Figure 5, a clear relation between water recovery, feed concentration and heat transfer area is seen. Figure 5 shows that for feed mixtures below $5 \mathrm{wt} \%$ of ethanol, the recovery of the water as the heavy product in the stripping section is the most important variable. The energy requirements are 
reduced, therefore, at high water recovery ratios due to the lower total flow rates obtained after the stripping section, that consequently lower the compressor work and the condenser duty as the reflux becomes lower due to lower internal flow rates and easier separation. It can finally be seen, that several infeasible designs have been identified, especially for lower ethanol concentrations in designs with higher heat transfer areas. These designs lead to infeasible operations due to very low internal flow rates.

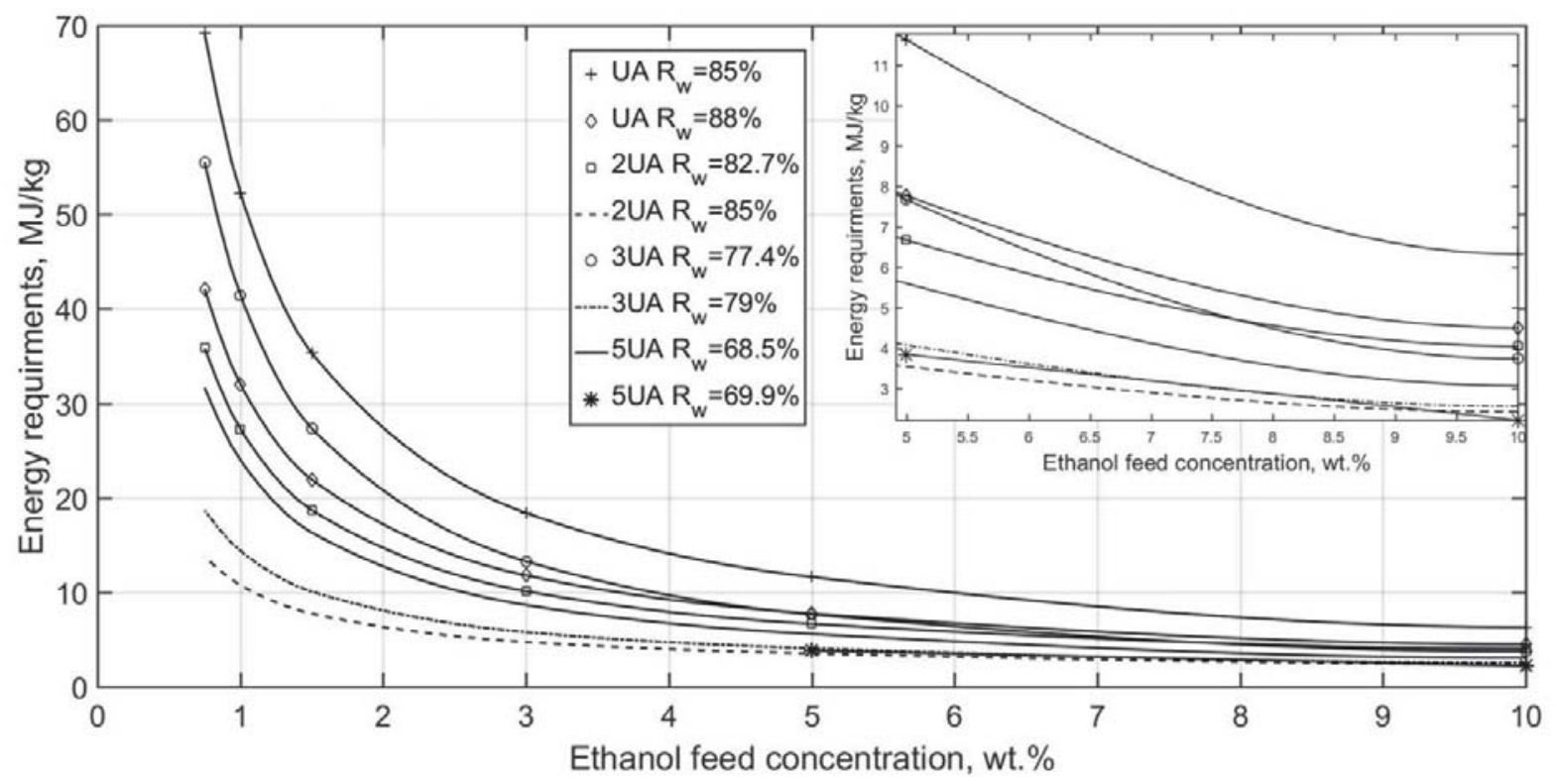

Figure 5. Energy requirements per $\mathrm{kg}$ of ethanol product with respect to ethanol feed concentration for different heat transfer areas and water recovery in stripping section. Energy requirement is the sum of reboiler and condenser duty and compressor work. Note: Water recovery in the stripping section refers to the amount of the water that is removed as a heavy product from the rectifying section (stream 3, S3) compared to the amount of the water that enters the column in stream 2 (S2), see Figure 2.

The simulation studies have shown that the performance of the diabatic horizontal separation system in terms of energy requirements depends on multiple variables. First, increased alcohol concentration in the feed lowers the specific energy requirements (energy per $\mathrm{kg}$ of product). Secondly, the water recovery as a heavy product in the stripping section significantly lowers the energy requirements as the overall flow rates (keeping ethanol productivity and recovery constant) are reduced. Design variables such as the heat transfer area and the phase contact area must be carefully selected and evaluated as opposite effects from the expected ones might occur in case of over-design. Similar observations related to heat transfer area have been made by Bisgaard et al. (2017b). As an overall conclusion, the necessary decisions required to design and operate such a heat-integrated system are not straightforward. 


\section{Comparative study-Conventional distillation column}

A conventional vertical distillation system has been set up and compared to the horizontal separation system with and without heat integration. The purpose of this study is to demonstrate any potential energy savings of the horizontal system when compared to the baseline system. The recovery of most of the light alcohols and removal of the water and temperature sensitive components without the use of solid-liquid separation system are the criteria of the separation. Table 1 lists the input variables for the vertical distillation column, the variables for the horizontal separation system without heat integration, and the variables used for the simulation of the heat integrated horizontal system. For the heat integrated system, a heat transfer area of $1 \cdot \mathrm{UA}$ has been considered. The results are shown in Figure 6. The comparison illustrates the energy demands of each system to achieve the same separation in terms of ethanol product flow rate, ethanol recovery and ethanol purity in the product stream. The results show that the integrated horizontal system has promising potential energy savings.

380 Table 1. Input variables and the specifications for the conventional distillation column.

\begin{tabular}{|c|c|c|c|c|}
\hline Input Variables & $\begin{array}{l}\text { Vertical } \\
\text { column }\end{array}$ & Horizontal & $\begin{array}{l}\text { Heat } \\
\text { integrated }\end{array}$ & Reference/Comment \\
\hline Inlet flow rate & $0.1 \mathrm{kmol} / \mathrm{sec}$ & $0.1 \mathrm{kmol} / \mathrm{sec}$ & $0.1 \mathrm{kmol} / \mathrm{sec}$ & Specified \\
\hline Inlet temperature & $40^{\circ} \mathrm{C}$ & $40^{\circ} \mathrm{C}$ & $40^{\circ} \mathrm{C}$ & $\begin{array}{l}\text { Fermentation effluent } \\
\text { temperature }\end{array}$ \\
\hline $\begin{array}{ll}\text { Ethanol feed } \\
\text { concentration }\end{array}$ & $1-10 \mathrm{wt}-\%$ & $1-10$ wt- $\%$ & $1-10 \mathrm{wt}-\%$ & Specified \\
\hline Heat transfer area & - & - & $(1-5) \cdot \mathrm{UA}$ & \\
\hline Column pressure & $0.1 \mathrm{~atm}$ & & & Specified \\
\hline Stripper pressure & & $0.1 \mathrm{~atm}$ & $0.1 \mathrm{~atm}$ & \\
\hline Rectifier pressur & & $0.3 \mathrm{~atm}$ & $0.3 \mathrm{~atm}$ & \\
\hline Number of trays & 15 & - & - & $\begin{array}{l}\text { Calculated } \\
\text { method) }\end{array}$ \\
\hline Feed location & 5 (from the top) & See Fig. 2 & See Fig. 2 & $\begin{array}{l}\text { Calculated } \\
\text { method) }\end{array}$ \\
\hline \multicolumn{5}{|l|}{ Specifications } \\
\hline Ethanol purity, top & 93 wt. $\%$ & 93 wt. $\%$ & 93 wt. $\%$ & Specified \\
\hline Ethanol recovery & $93 \%$ & $93 \%$ & $93 \%$ & Specified \\
\hline Reflux ratio & 3.94 & 4.5 & 0.15 & Manipulated variable \\
\hline Boilup ratio & & 0.5 & 2.5 & Manipulated variable \\
\hline
\end{tabular}




\section{Comparative studies}

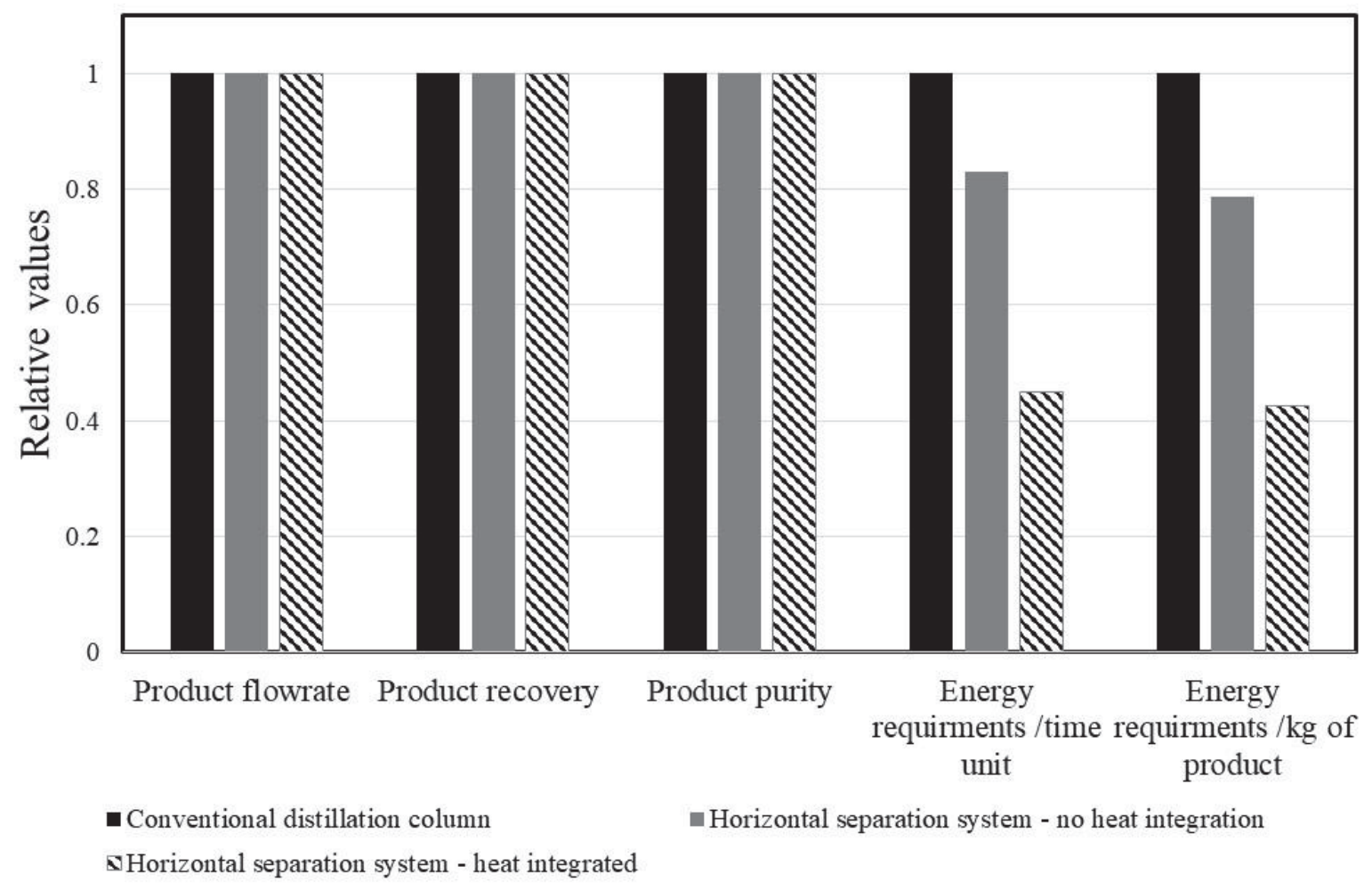

Figure 6. Comparative studies between a heat integrated horizontal separation system, a non-heat integrated separation system and conventional vertical distillation system.

\section{Economic studies}

388 The objective of this section is to explore a simple economic model of capital and operating expenditures, and to use these as process performance indicators to further support decisions regarding the design and to further reinforce the comparative studies of the horizontal separation system.

\subsection{Economic analysis}

The developed economic model is used to calculate the total equipment cost in the four different design scenarios listed in Table 2. Each scenario is examined based on the heat transfer area and the water recovery as a bottom product in the stripping section for different ethanol feed concentrations. In Table 2, the range of water recovery values as heavy product in the stripping section that allow the maximum ethanol recovery as light product in the stripping section are listed. The system specifications related to ethanol flow rate, recovery and purity of ethanol in the product stream (light product in the rectifying section) for each case of ethanol feed concentration are kept constant. 
403 Table 2. Design scenarios taken into consideration for the economic analysis.

\begin{tabular}{|c|c|c|}
\hline Design Scenario & Heat transfer area & $\begin{array}{c}\text { Water recovery as heavy product in } \\
\text { the stripping section }\end{array}$ \\
\hline 1 & $2 \times \mathrm{UA}$ & $82.7 \%$ \\
\hline 2 & $3 \times \mathrm{UA}$ & $77.4 \%$ \\
\hline 3 & $5 \times \mathrm{UA}$ & $68.5 \%$ \\
\hline 4 & $5 \times \mathrm{UA}$ & $69.5 \%$ \\
\hline
\end{tabular}

404

405

406

407

408

409

\subsubsection{Equipment cost}

The equipment cost for all the design scenarios is shown in Figure 7 for alcohol feed concentrations of $10 \mathrm{wt} \%, 5 \mathrm{wt} \%$ and $1 \mathrm{wt} \%$. The biggest contribution to equipment cost comes from compressors and the horizontal system (evaporator and horizontal vessel) while the cost of reboiler and condenser, as expected, contribute insignificantly to the heat integrated systems.
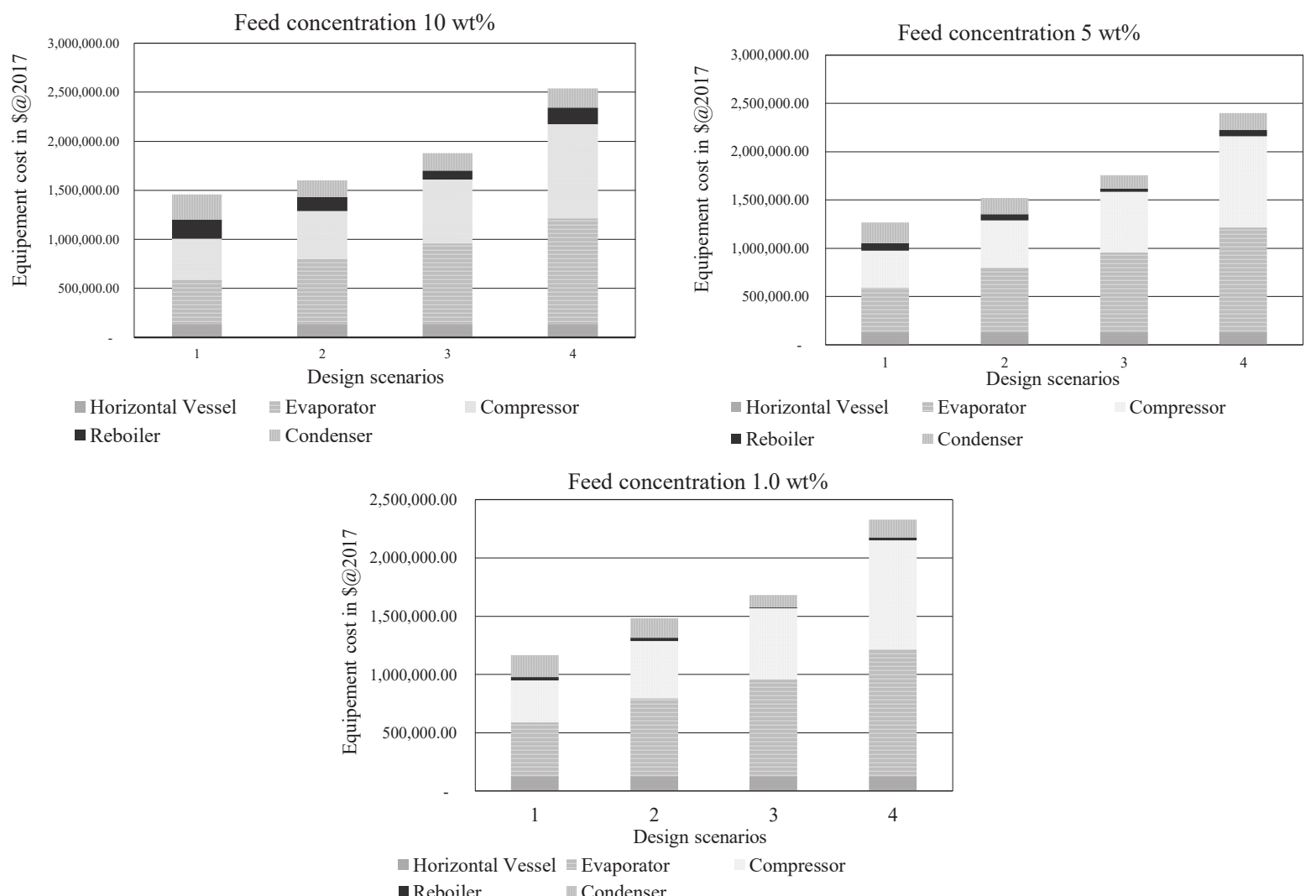

410 Figure 7. Equipment cost contribution considering four design scenarios for feed concentration of 10, 5 and 1 411 wt $\%$.

412 Figure 7 illustrates the equipment cost for each scenario for selected ethanol feed concentrations. 413 Therefore, looking at Figure 7, the design with the lowest equipment cost can be identified for each 

scenarios 1 and 2 demonstrate lower equipment costs as cost of the horizontal evaporator is lower due to the smaller heat transfer area.

\subsubsection{Utilities cost}

418 The analysis of the equipment cost needs to be coupled with the analysis of the utilities cost. The prices for the utilities have been collected considering three locations of interest: Europe, the USA and Brazil. Used prices of water and electricity (for industrial use) are listed in Table 3. For heating purposes, three types of steam (high, medium and low-pressure steam) are considered for the analysis. The price values used are also listed in Table 3.

Table 3. Prices of utilities (water and electricity) depending on the location country.

\begin{tabular}{|c|c|c|c|c|c|}
\hline Location & $\begin{array}{l}{ }^{1} \text { Prices of } \\
\text { cooling water, } \\
\$ / \mathbf{m}^{3}\end{array}$ & Electricity $\$ / \mathbf{k W h}$ & HPS \$/kg & MPS \$/kg & LPS \$/kg \\
\hline Europe & 0.084 & $0.114^{2}$ & \multirow{3}{*}{$6.48^{5}$} & \multirow{3}{*}{$5.47^{5}$} & \multirow{3}{*}{$4.03^{5}$} \\
\hline USA & 0.053 & $0.0679^{3}$ & & & \\
\hline Brazil & 0.0526 & $0.1-0.2^{4}$ & & & \\
\hline
\end{tabular}

Note: Data for utilities prices has been collected from online sources accessed on February 2018.

${ }^{1}$ https://www.intratec.us/chemical-markets/cooling-water-price,

2 http://ec.europa.eu/eurostat/statistics-explained/index.php/Electricity price statistics,

3 https://www.eia.gov/electricity/monthly/current month/epm.pdf,

$4284 \mathrm{https} / /$ www.statista.com/statistics/263492/electricity-prices-in-selected-countries/

$429 \quad 5$ Towler and Sinnot (2013)

431 The results for mixtures with $10 \mathrm{wt} \%$ of ethanol are shown in Figure 8a, where the total operational 432 cost is given for each design scenario in three distinct locations. It appears that the operational cost 433 is lower in the USA, due to lower electricity prices. The operational cost is slightly lower in Brazil 434 compared to Europe due to the slight differences in utilities prices. For Europe and Brazil, the 435 design scenario 2 appear to have the lowest operational costs followed by design scenario 1 and 3. 436 In case of U.S. design scenarios 3 has the lowest operational costs followed by scenario 2 and 1 437 while the operation cost of design scenario 4 is slightly higher. 
(a)

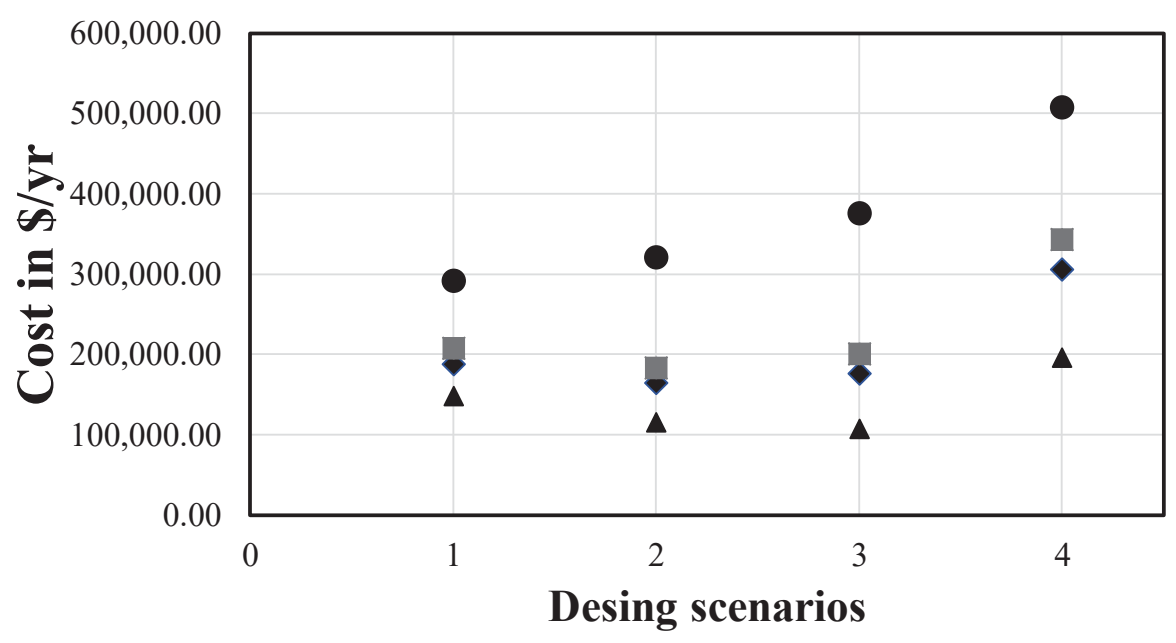

$\Delta$ USA Brazil Europe - Total equipement cost (\$/yr@ 2017)

(b)

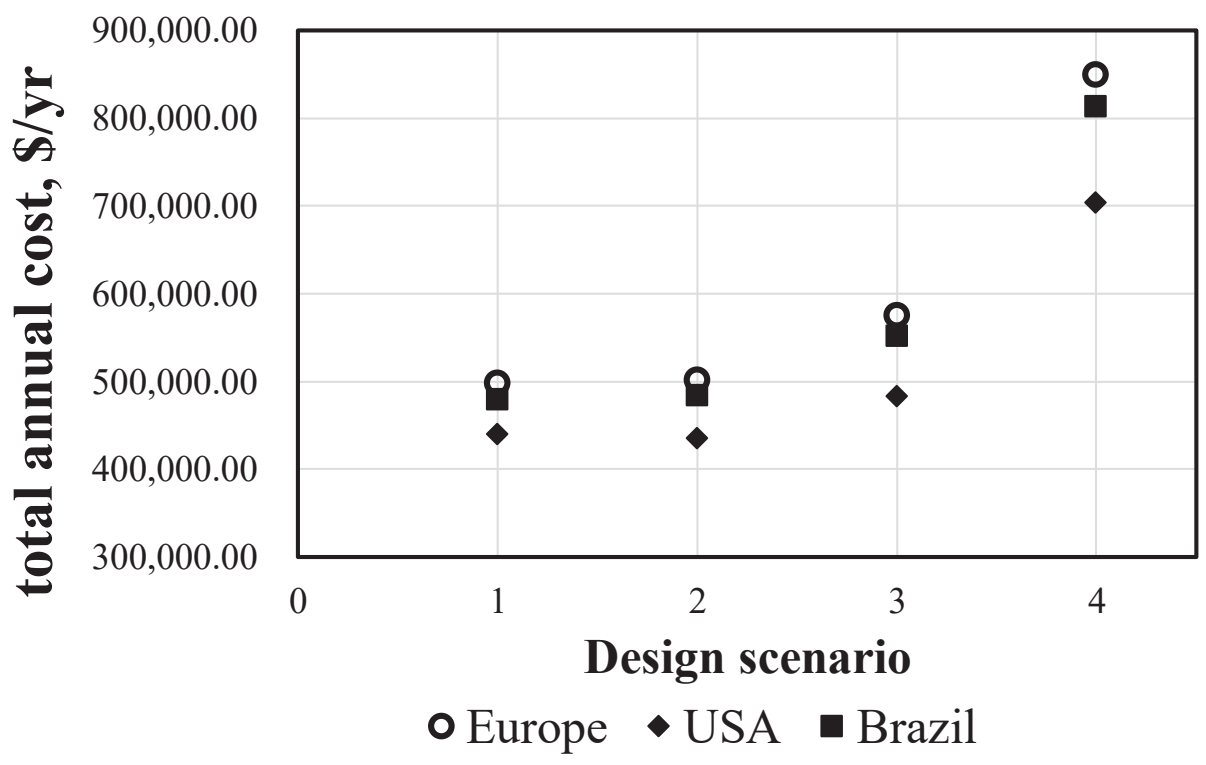

Figure 8. (a) Operational cost for the horizontal separation system in three different locations (EU, US and BR). (b) Total annual cost in \$ per y, considering $10 \mathrm{wt}-\%$ ethanol concentrations for all the design scenarios in different locations (EU, USA, and Brazil).

Until now, the process analysis has shown that many variables affect the process performance in terms of economics and energy demands. In Figure 8b, the total operational cost is shown for all the design scenarios in three distinct locations where the market of utilization of biomass is important. The total annual cost per year is calculated as the summation of the operational and capital (in $\$$ per year, the equipment is assumed to have approximately 5 years operational life-time). Figure $8 \mathrm{~b}$ shows that operation in the USA leads to lower total annualized operational costs while operation in Europe and Brazil leads to higher operational costs. Regardless of the location, it appears that the 
lowest operational costs are associated with design scenarios 1 and 2, which correspond to designs with relatively low heat transfer areas (2 and 3·UA). Horizontal separation systems with higher heat transfer areas require less heat and cooling utilities but have higher compression needs and therefore, the resulting equipment leads to higher capital and operational costs.

The economic model has been developed on the basis of previously developed cost correlations that represent parts of the horizontal separation system. However, biorefinery technologies involve state-of-the art equipment and it is a highly costly in terms of capital investments (Tsagkari et al. 2016). Therefore, based on the economic analysis, there is a need (as it has also been accurately highlighted by Tsagkari et al. 2016) for developing accurate cost correlations and tools for capital cost estimations to assist with the preliminary evaluation, design and decision making in the early stage design of biorefineries.

\section{Discussion}

The discussion is divided into aspects related to modeling and optimization.

\subsection{Model development and applications}

To improve such an analysis and use the model for decision making at the early stage of the equipment design, experimental data to estimate the values and the uncertainties in model parameters such as the transport coefficients and to assess the system performance are required. Additionally, the horizontal system needs to be analyzed and evaluated in dynamic state to evaluate possible control strategies and important operational scenarios such as shut downs and start-ups. Furthermore, the economic model must be validated and reassessed using industrial cost estimation data when available. Another interesting application of the horizontal system that has not been evaluated in this study is to be used as replacement of the energy intensive beer column to concentrate the fermentation liquid coming from $1 \mathrm{G}$ (or $2 \mathrm{G}$ ) biomass utilization. The replacement of the beer column might offer significant advantages in rejecting a big part of the water and the heavier compounds resulting after the fermentation at lower overall energy demands.

\subsection{Process optimization}

At this point, the analysis should be moved forward by first, considering other separation technologies and compare these in terms of energy and economics using benchmarking models. Secondly, assess the overall impact of using such a technology (with all the characteristics described in Section 2) by considering the overall picture of bio-refineries chain, implying solution of MILP and/or MINLP optimization problems. The optimization problem needs to consider the dependence upon the location, with all the available data for biomass resources (preferably $2 \mathrm{G}$ biomass that is not involved in any way in the food chain), the conversion technologies (chemical or biochemical), the possible separation technologies, the recycle streams, if required and potential products (single or multiple products, and bioenergy) and their prices (Bertran et al. 2017). Finally, the analysis will be thorough when the model is combined with functions, which can calculate the transportation costs, quantify impact categories for sustainability metrics in terms of socioenvironmental aspects (Antizar-Ladislao et al. 2008), has options for centralized and localized biorefineries and is coupled with sensitivity and uncertainty analysis tools. 


\section{Conclusions}

An engineering tool based on process systems engineering methods has been developed to assist with the preliminary evaluation and analysis of a heat integrated horizontal separation system in absense of experimental data. Analysis has shown that the model describes qualitatively what would be expected of the system, and it is in good agreement with the theoretical expectations. The effect of transport coefficients, calculated considering packed stages and known correlations, has been assessed with sensitivity analysis, showing that primarily sensitivity to mass transfer coefficients exists. Through simulation studies, operational and design limitations have been investigated by varying important design variables such as the heat transfer area between the rectifying- stripping section and the phase contact area as a function of process specifications such as light product purity, water removal and ethanol recovery. The analysis has shown that increased water removal decreases significantly the operating costs and interestingly increased heat transfer area does not lead to operation with lower energy requirements. Finally, an economic analysis performed using known correlations of cost models for a horizontal evaporator, horizontal vessel, condenser and reboiler has been explored. Through the economic analysis multiple design scenarios for different biorefinery locations of interest have been compared. OPEX analysis showed that the operating cost is lower in locations with lower electricity prices. In general, designs with heat transfer area (23UA) appear to have lower operating costs compared to design with higher heat transfer area. However, in a location with low electricity prices and water removal close to the maximum the operating costs of a unit with high heat transfer area become comparable to the designs with lower heat transfer area. The CAPEX analysis showed, as expected, an exponential increase in capital costs with increased heat transferred area. Finally, the total annual cost analysis shows that the lowest annual costs are achieved when the heat transfer area is between 2-3UA and designs with high heat transfer area become economically feasible only in locations with low electricity prices and after optimization.

Finally, a superstructure within the field of biorefineries that considers the current technologies (including the horizontal separation system as replacement of the beer column and/or as separation module to obtain pure alcohol), location dependency, transportation costs, availability of biomass, and integration in terms of processing steps and type of biomass and type of products could be envisioned. This evaluation will probably demonstrate under which conditions, at current times, the local-based bio refineries, which utilize new or old technologies are viable options over the bioenergy produced by $1 \mathrm{G}$ biomass utilization.

\section{Acknowledgement}

The authors would like to acknowledge the financial support of the SYNFERON (journal no. 410600035B by Innovation Fund Denmark) project.

\section{Nomenclature}

\begin{tabular}{|l|l|l|}
\hline Symbol & Description & Units \\
\hline A & Heat transfer area & $\mathrm{m}^{2}$ \\
\hline D & Diameter & $\mathrm{M}$ \\
\hline $\mathrm{f}$ & Factor $(0-1)$ & \\
\hline
\end{tabular}




\begin{tabular}{|c|c|c|}
\hline $\mathrm{h}$ & Heat transfer coefficient & $\mathrm{W} / \mathrm{m}^{2} \mathrm{~K}$ \\
\hline $\mathrm{k}$ & Mass transfer coefficient & $\mathrm{m} / \mathrm{s}$ \\
\hline $\mathrm{L}$ & Length & M \\
\hline $\mathrm{N}$ & Number of segments & \\
\hline $\mathrm{n}$ & Factor (1-5) & \\
\hline $\mathrm{P}$ & Pressure & Atm \\
\hline Q & Heat duty & $\mathrm{kJ} / \mathrm{sec}$ \\
\hline $\mathrm{R}_{\mathrm{w}}$ & $\begin{array}{l}\text { Water recovery: ratio of water flowrate in stream } 3(\mathrm{~S} 3) \text { and } \\
\text { water flowrate in stream } 2 \text { (S2). }\end{array}$ & \\
\hline $\mathrm{S}$ & Stream & - \\
\hline $\mathrm{T}$ & Temperature & $\mathrm{K}$ \\
\hline $\mathrm{U}$ & Heat transfer coefficient (wall) & $\mathrm{W} /\left(\mathrm{m}^{2} \mathrm{~K}\right)$ \\
\hline $\mathrm{W}$ & Compressor work & $\mathrm{kW}$ \\
\hline$\Delta \mathrm{T}$ & Temperature difference & $\mathrm{K}$ \\
\hline \multicolumn{3}{|l|}{ Subscripts } \\
\hline $\mathrm{C}$ & Compressor & \\
\hline con & Condenser & \\
\hline $\mathrm{i}$ & Number of compounds $(1, \ldots, C)$ & \\
\hline $\mathrm{j}$ & Number of segments $(1, \ldots, \mathrm{N})$ & \\
\hline $\min$ & Minimum & \\
\hline reb & Reboiler & \\
\hline \multicolumn{3}{|l|}{ Superscripts } \\
\hline I & Interface & \\
\hline $\mathrm{L}$ & Liquid phase & \\
\hline $\mathrm{S}$ & Stripper & \\
\hline $\mathrm{R}$ & Rectifier & \\
\hline V & Vapor phase & \\
\hline $\mathrm{W}$ & Wall (or water) & \\
\hline \multicolumn{3}{|l|}{ Abbreviations } \\
\hline $1 \mathrm{G}$ & First generation biomass & \\
\hline $2 \mathrm{G}$ & Second generation biomass & \\
\hline AEs & Algebraic equations & \\
\hline ASPEN Plus & Process simulator & \\
\hline $\mathrm{BC}$ & Base cost & \\
\hline $\mathrm{BR}$ & Brazil & \\
\hline CAPEX & Capital expenditures & \\
\hline $\mathrm{CO}_{2}$ & Carbon dioxide & \\
\hline EU & Europe & \\
\hline GHG & Green house gases & \\
\hline HIDiC & Heat integrated distillation column & \\
\hline MERSHQ & Mass-energy-rate-summation-hydraulic-equilibrium & \\
\hline NIST & National Institute of Standards and Technology & \\
\hline OPEX & Operation expenditures & \\
\hline USA & United State of America & \\
\hline UMC & Updated modular cost & \\
\hline VLE & Vapor Liquid equilibria & \\
\hline
\end{tabular}




\section{References}

Aditiya, H. B., Mahlia, T. M. I., Chong W. T., Nur H., Sebayang A. H., 2016. Second generation bioethanol production: A critical review. Renew. Sust. Energ. Rev. 66, 631-653.

Almeida, J. R. M., Fávaro, L. C. L., Quirino, B. F., 2012. Biodiesel biorefinery: opportunities and challenges for microbial production of fuels and chemicals from glycerol waste. Biotechnol. Biofuels. 5 (48), 1-16.

Antizar-Ladislao, B., Turrion-Gomez, J. L., 2008. Second-generation biofuels and local bioenergy systems. Biofuels, Bioprod. Bioref. 2,455-469.

Bertran, M-O., Frauzem, R., Sanchez-Arcilla, A. S., Zhang, L., Woodley, J., Gani, R., 2017. A generic methodology for processing route synthesis and design based on superstructure optimization. Comp. Chem. Eng. 106, 892-910.

Biegler, L. T., Grossmann I.E., Westerberg A. W., 1997. Systematic methods of chemical process design. pg. 796, Prentice Hall PTR.

Bisgaard, T., Huusom, J. K., Abildskov, J., 2015. Modelling and analysis of conventional and heatintegrated distillation columns. AIChE J. 61(12), 4251-4263.

Bisgaard, T., Mauricio-Iglesias, M., Huusom, J. K., Gernaey, K. V., Dohrup, J., Petersen, M. A., Abildskov, J., 2017a. Adding Value to Bioethanol through a Purification Process Revamp. Ind. Eng. Chem. Res. 56 (19), 5692-5704.

Bisgaard, T., Skogestad, S., Abildskov, J., Huusom, J. K., 2017b. Optimal operation and stabilising control of the concentric heat-integrated distillation column (HIDiC). Comp. Chem. Eng. 96, 196211.

Bravo J. L., Rocha J. A., Fair J. R., 1985. Mass transfer in gauze packings. Hydrocarb. Processes. 64, 91-95.

Bossel, J. J., Petersen, G. P., 2010. Technology development for the production of biobased products from biorefinery carbohydrates - the US Department of Energy's “Top 10"revisited. Green Chem. 12, 539-554.

Chang, L., Xinggao, L., 2014. Non-equilibrium stage based modeling of heat integrated air separation columns. Sep. Purif. Technol. 134, 73-81.

Eckey, W. E., 1959. Method for continuous multistage countercurrent contacting of liquids with vapors. US $2,871,250 \mathrm{~A}$.

Heitzig, M., Rong, Y., Gregson, C., Sin, G., Gani, R., 2012. Systematic Multi-Scale Model Development Strategy for the Fragrance Spraying Process and Transport. Chem. Eng. Technol. 35, 1381-1391. 
Jang D. J., Kim, Y. H., 2015. A new horizontal distillation for energy saving with a diabatic rectangular column. Korean J. Chem. Eng. 32, 2181-2186.

Jensen, E., 2005. An apparatus for rectification of liquid mixtures and/or for scrubbing of gases. U.S. $6,884,284 B 1$.

Kim B. C., Chun H. H., Kim Y. H., 2013. Energy-efficient diabatic distillation using a horizontal distillation column. Ind. Eng. Chem. Res. 52, 14927-14935.

Lee, Y.S., Kim, M.G., Ha, D.M., Oda, A., Ito, C., Aragaki T., Hideki, Mori., 1997. Analysis of packed distillation columns with a rate-based model. Korean J. Chem. Eng. 14, 321-324.

Mueller, I., Kenig, E. Y., 2007. Reactive Distillation in a Dividing Wall Column: Rate-Based Modeling and Simulation. Ind. Eng. Chem. Res. 46 (11), 3709-3719.

Papadakis E., Mansouri S.S., Huusom J.K., Abildskov J., 2018a. Analysis and evaluation of a heat integrated horizontal distillation system, Computer Aided Chemical Engineering, 44: 217-222.

Papadakis, E., Mansouri, S.S., Huusom, J.K., Abildskov, J., 2018b. Analysis and evaluation of a heat integrated horizontal distillation system. Chemical Engineering Transactions, 69: 643-648.

Peng J., Lextrait S., Edgar T. F., Eldridge R. B., 2002. A comparison of steady-state equilibrium and rate-based models for packed reactive distillation columns. Ind. Eng. Chem. Res. 41 (11), 27352744.

Peng, J., Edgar, T. F., Eldridge, R. B., 2003. Dynamic rate-based and equilibrium models for a packed reactive distillation column. Chem. Eng. Sci. 41 (11), 2735-2744.

Peters, M.S., Timmerhaus, K. D., West, R.E., 2003. Plant Design and Economics for Chemical Engineers. pg. 988, McGraw-Hill Education.

Ramirez-Gonzalez, E. A., Martinez, C., Alvarez, J., 1992. Modeling Zero-Gravity Distillation, Ind. Eng. Chem. Res. 31, 901-908.

Seok, D. R., Hwang, S. T., 1985. Zero-Gravity Distillation Utilizing the Heat Pipe Principle (Microdistillation), AIChE J. 31, 2059-2065.

Taylor, R., Krishna, R., 1993. Multicomponent Mass Transfer. New York.

Taylor, R., Krishna, R., Kooijman, H., 2003. Real world modelling of distillation. Chem. Eng. Prog. 99 (7), 28-38

Towler, G., Sinnot, R., 2013. Utilities and Energy Efficient Design. In Chemical Engineering Design: Principles, Practice, and Economics of Plant and Process Design. Elsevier Ltd. 103-159.

Tsagkari, M., Couturier, J. L., Kokkosis, A., Dubois J. L., 2016. Early-stage capital cost estimation of biorefinery processes: A comparative study of heuristic techniques. Chem. Sus. Chem. 9, 22842297. 
590 Wyss, J. F., Uzwil, P., 1980. Thin layer evaporators. U.S. Patent 4,193,837. 